\title{
From toothpick legs to dropping vaginas: \\ Gender and sexuality in Joan Rivers' stand-up comedy performance
}

\author{
Sharon Lockyer, Brunel University
}

\begin{abstract}
This article employs sociocultural analysis to examine Joan Rivers' stand-up comedy performances in order to reveal how she successfully operates in a sphere of artistic expression that has been, and continues to be, male-dominated. The analysis uncovers how Rivers' stand-up comedy performance involves a complex combination of elements and how it fuses features that are regarded as 'traditionally masculine', such as aggression, with features frequently used by other female stand-up comedians, such as self-deprecating comedy and confessional comedy. Furthermore, the analysis exposes the complex ways in which constructions of gender and sexuality are negotiated and re-negotiated in Rivers' stand-up comedy performance, and illustrates how dominant ideological identity constructions can be simultaneously reinforced and subverted within the same comic moment.
\end{abstract}

\section{Keywords}

gender

sexuality

stand-up comedy

Joan Rivers

self-deprecation

ageing female body

masculine discourses

\section{Introduction}

A large body of academic and industry-related evidence suggests that the stand-up comedyscape has always been, and continues to be, male-dominated (Channel 4 2010; Chortle 2011; Gray 1994; Nilsen and Nilsen 2000; Ross 1998; Zoglin 2009). Such male dominance is reflected in the number of male stand-up comedians compared with female stand-up comedians and the aggressive performative features that this form of artistic expression utilizes, which are often perceived as 'traditionally male'. Despite this, female 
stand-up comedians can, and do, penetrate this male-dominated industry and have successful stand-up comedy careers. This article examines how one eminent female stand-up comedian, Joan Rivers, negotiates this predominantly male space through close qualitative sociocultural analysis of her stand-up comedic performance. The specific Live at the Apollo (Wheeler 2007) performance chosen for analysis is interrogated in order to answer three inter-related questions: how does Rivers navigate the male-dominated stand-up comedy space? How does Rivers negotiate a form of expression that is largely aggressive and competitive? To what extent does Rivers use her stand-up comedy performance to reinforce or resist traditional dominant notions of gender and sexuality?

\section{Funny women? Don't make me laugh!}

There are many factors surrounding gender and stand-up comedy creation, performance and appreciation. These factors contribute to a 'masculine discourse' (see Beynon 2002; Smith 1996), which is designed to promote and maintain male power and dominance across the stand-up comedyscape. Zoglin (2009: 6) argues that the stand-up comedy landscape is largely 'defined by testosterone' and notes that conventional wisdom suggests that women are 'less suited by nature to stand-up comedy, an aggressive, take-charge art form' (Zoglin 2009: 182). Those female stand-up comedians who do penetrate this male-dominated sphere and adopt an aggressive tone are criticized for doing so. For example, the American TV host Johnny Carson (who provided the launch pad for many male comedians and also had Joan Rivers on his show as a regular guest) argued that stand-up comedy is 'much tougher for women[...] You don't see many of them around. And the ones that try, sometimes, are a little aggressive for my taste. I'll take it from a guy, but from a woman, sometimes, it just doesn't fit too well' (quoted in Zoglin 2009: 192). This male dominance in stand-up comedy is reflected in the current British live stand-up comedy circuit. Of the 58 comedians described as 'Comedians on Tour' on the Chortle: The UK Comedy Guide website in early April 2011, only seven (or 12 per cent) are women (including Zoe Lyons, Sarah Millican, Shappi Khorsandi and Shazia Mirza (Chortle 2011)).

Nilsen and Nilsen (2000) outline a number of reasons to explain the gender imbalance in stand-up comedy performers. They argue that stand-up comedy is highly competitive, and male stand-up comedians, who do not wish to have increased competition, have endeavoured to maintain separate gender stand-up comedy factions; female stand-ups are more likely to be heckled and criticized; some comedy promoters insist that female stand-ups are not loud or 
strong-enough performers to close/headline performances; and that some audiences, despite the advances and reforms of the feminist movement, are not prepared to afford women the powerful position that a stand-up comedian has the potential to adopt. Furthermore, Ross (1998) and Gray (1994) have independently pointed out the myth that exists that maintains that women do not possess a sense of humour, which is perceived as hindering their comedy creation and appreciation.

Some journalists and comedy critics perpetuate negative stereotypes surrounding funny women and hold them liable for what some comedy critics view as detrimental changes in stand-up comedy styles. Hitchens (2007) commented in Vanity Fair that successful female comedians are 'hefty or dykey or Jewish', and St John (2005), in the article 'Seriously, the Joke is Dead', blames women for the demise of the 'short-story-with-a-punchline jokes' (along with political correctness and the Internet) due to their observational-type humour (cited in Carr and Greeves 2007: 157-158). As suggested by Nilsen and Nilsen (2000), audiences also seem to perpetuate male dominance in stand-up comedy. In 2005, the men's magazine FHM voted the UK's funniest women as 'none of them' (Carr and Greeves 2007: 165), and in April 2010, in an audience poll conducted by Channel 4 entitled, the ' 100 Greatest Stand-Ups of All Time', only six women made it to the top 100. Victoria Wood was the woman who was ranked the highest at 10th place, with Jo Brand reaching 30th, Jenny Eclair at 70th, Roseanne Barr at 93rd and Shappi Khorsandi at 99th. The focus of this article, Joan Rivers, was ranked 57th (Channel 4 2010). These polls reflect the findings of scientific studies, such as those conducted by Provine (1996), which suggest that both males and females laugh at male comedians more than they do at female comedians. Joan Rivers herself seems to perpetuate the masculine discourse surrounding stand-up comedy. She has argued:

I don't like funny women. I come out of that generation where a woman should be beautiful and sexy and a wonderful flower attached to a man, even though my whole life has been the antithesis of this. To this day, you don't expect a woman to be funny. (Horowitz 1997: 103)

However, a number of women, from Victoria Wood and Dawn French to Jo Brand and Jenny Éclair, have productively negotiated this male-dominated performance space, have successful stand-up comedy careers, and challenge the masculine stand-up comedy discourses. There has been a steady increase in the number of female stand-up comedians performing in American comedy clubs. In 1990 Time magazine reported that in 19702 per cent of stand-up 
comedians were female compared with 20 per cent in 1990 (cited in Nilsen and Nilsen 2000: 137). One of the most successful female stand-up comedians is Joan Rivers. Although she has argued:

Comedy is masculine. To stand up and take control of an audience verbally is very difficult. Women are oppressed in childhood and not allowed to do this. Also, women want to be attractive, and comics are not supposed to be that way. (Horowitz 1997: 107)

Joan Rivers has a comedy career spanning five decades and thus is, to some comedy industry professionals and comedy audiences, a funny woman. The foundations of Rivers' comedy career were laid at a time when the comedy industry was more male-dominated than it is today. As she has continued to be successful across five decades, it is important and interesting to consider the dynamics of her stand-up comic performance in terms of gender. It is to such dynamics that we turn our attention by closely examining Rivers' performance. The chosen performance is Live at the Apollo (Wheeler 2007) originally broadcast on 10 December 2007. It was hosted by Joan Rivers and included Patrick Kielty as the guest comedian. Data for the article were gathered from two YouTube videos of this broadcast Part 1 (9 minutes and 56 seconds in duration) and Part 2 (6 minutes and 11 seconds in duration) - in which we see Rivers open and close the show. ${ }^{1}$

\section{Balancing the gender-imbalanced comedyscape}

Much of Rivers' stand-up performance at Live at the Apollo is aggressive in tone and content. ${ }^{2}$ This aggression is directed towards either herself, through the use of selfdeprecating comedy, celebrities and/or image-obsessed Western culture. Across her comedy career, and in the clips chosen for analysis in this article, Rivers has joked about her nonexistent love life. Whether single, married or widowed, the main thrust of Rivers' comedy persona has remained the same - 'Joan is the sexual loser, the ugly girl whom no man wants' (Horowitz 1997: 98). For example, in the Live at the Apollo performance, Rivers' topics of conversation suggest she has few, if any, sexual relationships with others:

Cos it's all about looks. This is my message Great Britain. This is my message. Looks count, education pah. Looks count. I've had no sex appeal and it has screwed me up 
for life. Peeping Toms look at my window and pull down the shade. You have no idea. My gynaecologist examines me by telephone. (Part 1, 9:01-9:22)

Rivers also discusses her childhood experiences and her difficult relationship with her parents:

My parents hated me OK, we're all gonna hear the story 'my parents hated me too'. All I ever heard, all I ever heard growing up was 'Why can't you be like your cousin Sheila, why can't you be like your cousin Shelia?', Sheila had died at birth. They just hated me. (Part 1, 6:01-6:23)

Self-deprecating jokes were used by other women who shared the comedy landscape with Joan Rivers in the 1960s when there were fewer female stand-up comedians than today. For example, Phyllis Diller and Totie Fields both joked about their appearance and body shape/size in a derogatory manner (see Horowitz 1997). Such self-deprecating comedy used by these female stand-up comedians is based on negative female stereotypes, which are exaggerated for humorous effect (Horowitz 1997). Self-deprecating comedy is used by some stand-up comedians as a rhetorical strategy. When explaining her own use of self-deprecating comedy, Jo Brand maintains:

I've always felt that the putting-yourself-down stuff did give you a bit of a ticket to go on and lay into someone else. Also, it gets it out of the way. Because as a woman you know when you come on stage the first thing you're judged on is your appearance. (Wagg 1998: 134)

As Horowitz argues, self-deprecating comedy eases the resistance to the idea of a woman comic - 'the logic being that if you're doing something women aren't supposed to do, you might be accepted if you show that you don't think much of yourself as a woman' (1997: $103)$.

Furthermore, Gray argues that self-deprecation 'only works if it is clearly perceived to be an act' (1994: 137, original emphasis). Some of the self-deprecating comedy in Rivers' stand-up performance does appear to be an act. Rivers is a sophisticated woman - her carefully manicured nails, a face and body manipulated by cosmetic surgery, her expensive jewellery and her well-groomed hair suggest that she is far removed from the woman she describes as 
having no sex appeal. The comedy lies in the incongruity and exaggerated differences between Rivers' actual appearance and her self-perception (see Brett Mills' article in this issue for more on incongruity in Rivers' stand-up comedy performance).

Rivers' self-deprecating comedy may also serve to reduce the sociocultural distance between her, the performer, and the (non-celebrities in the) audience. Horowitz argues that River's self-deprecatory comedy 'evokes empathy and assures them [the audience] that underneath, she is like them - an outsider who feels like a loser' (1997: 99) despite her celebrity status and financially secure lifestyle. Self-deprecating jokes 'often surprise and amuse listeners or readers and leave them feeling superior to the comedian' (Nilsen and Nilsen 2000: 273). They shift the power from Rivers to the audience, thus making the woman on stage more palatable for those audience members who may feel threatened by seeing a woman on stage. The use of self-disparaging jokes may also be a direct appeal to women in the audience, as Zillman and Stocking (1976) found that women have a preference for self-disparaging jokes. Men dislike self-disparaging jokes, particularly when made by females. Palmer suggests that this may be explained 'on the ground that they [males] so much like mockery of female others that self-disparagement by a female takes the fun out of the situation' (1994: 69). However, Rivers is not simply just a victim; she is an aggressor too who mocks and ridicules others, particularly celebrities. In her Live at the Apollo appearance, Rivers begins her standup performance by making a number of jokes at the expense of some of the male and female celebrities in the audience (e.g. Eamonn Holmes and Ruth Langsford, Gok Wan, James Nesbitt and Craig Revel Horwood; Part 1, 0:21-2:29). Targeting celebrities and celebrity culture is one of Rivers' comedy trademarks (see Rivers and Meryman 1986). We see Rivers joke about the 'pelican lips' of Angelina Jolie (Part 1, 3:45), the 'toothpick legs' of Katie Holmes (Part 1, 05:40-05:44) and the difficulties experienced by Heather McCartney in a tap dancing class - 'a great little tapper, but, you know, just one way... She kept falling down in the hokey cokey' (Part 1, 2:10-2:29). As Horowitz suggests, 'in her comedy act, she becomes both the ugly, teased scapegoat and the catty schoolmates who inflict the teasing' (1997: 99). Rivers intersperses the jokes made at the expense of others with self-deprecating jokes, or combines self-deprecating jokes and the teasing of others within the same comic moment:

I actually belong to over-eaters anonymous. Does anyone here belong? Except you're anonymous don't answer. The lousy thing is that they don't serve hors d'oeuvres, but the meetings are very interesting because these big fat ladies sit and cry and they go 
like nobody loves me, which is not true, because the butcher loves them, the baker loves them. One woman said, stood up and said, 'They made me buy two seats in the aeroplane'. And I said 'Yes, but you got two meals' and she perked right up. (Part 2, $4: 36-5: 10)$

Although Rivers has a slender body, which implies that she does not over-indulge and thus that the self-deprecating joke is an act, she has suffered from eating disorders, in which overeating and body dysmorphia were component parts (Rivers 1997), which offers an element of plausibility to the self-deprecating joke. This signals to the audience that she has the ability to recognize her own flaws and not just the flaws of others; thus, she has comic licence to target both herself and others.

\section{Reinforcing/resisting dominant notions of gender and sexuality}

This fluidity of laughing at both herself and others is also evident when considering the extent to which Rivers uses her stand-up comedy performance to reinforce or resist traditional dominant notions of gender and sexuality. Female comedians, such as Jo Brand and Jenny Éclair, have often used topics and issues related to the female biology (menstruation and childbirth) as comic material (see Gray 1994). Joan Rivers extends this comic repertoire to the physiology of the older woman. She proffers a complex combination of idiosyncrasies that simultaneously reinforce and resist western stereotypes about older women, their bodies and their sexuality. Cohen argues that 'to be old in our [western] society is to be devalued. To be old and female is to experience double oppression' (2002: 599; see also Sontag 1972). A large body of work exists which suggests that the western media offers a limited number and range of images of older women, which serve to perpetuate negative sociocultural stereotypes about older women (see Cohen 2002; Harwood and Giles 1992). When older women do appear in popular culture, they are often portrayed as 'being helpless, unknowledgeable, disoriented, or in some other unfavourable fashion' (Peterson and Ross 1997: 425). Other research demonstrates that negative portrayals of older women as eccentric and irrational are being replaced and resisted by increasing positive portrayals of older people as powerful, healthy, active and sexy (Bell 1992). One notable example is the American sitcom The Golden Girls (Terry Hughes, 1985-1992). ${ }^{3}$ The Golden Girls focussed on the lives of four 50-plus-year-old women who, due to divorce or widowhood, lived together in Miami, Florida. It was the first television programme in which all of the main characters were female and more than 50 years old. The sitcom was 'framed, at least initially, in terms of 
increasing the visibility, and likeability, of the elderly on prime time' (Harwood and Giles 1992: 405) and thus provided a welcome relief to the negativity that dominates the representations of older women in humorous television programming (e.g. see Barrick et al. 1990).

Rivers tackles taboos surrounding older women head-on. In the selected performance, Rivers intimately discusses issues exclusive to female biology, through what may be described as 'confessional stand-up'. In this instance, we are given access to issues related to the physiology of the ageing female body:

And you know when it changes for a woman, when you no longer have your period. Every woman in this room, enjoy your period. I don't wanna hear 'I've got cramps', you are, cos the minute you have no period, men couldn't give a shit. I'm telling you. To this day, I carry, because no man will look at you if they think you're over, I'm telling you, I still carry tampons in my purse. When no one's looking at me, I open my purse and a tampon drops out. Huh! I could just die. (Part 1, 9:24-9:56)

She continues:

Cos you know what, age, you'll all, it's a young audience, you know what it's like, age and it'll happen to all of you, ha, ha, ha, ha, ha. The body drops, my breasts, huh, I could have a mammogram and a pedicure at the same time... and this is horrible, do you know what really drops first? The vagina. No one tells you, the vagina drops. I woke up six months ago I went, 'why am I wearing a bunny slipper, and why is it grey?' (Part 2, 0:08-0:50)

This section of the routine is significant as it is reminiscent of Bakhtin's (1984) grotesque body. We see and hear an older woman talking about her own experiences of her ageing, protruding and misshapen body in an unfavourable and derogatory manner - we are given access to her menopausal experience and to her attempts to deceive others (men) into believing that her body has not reached this, in the words of Rivers, 'horrible', stage in her life. This may be viewed as reinforcing the popular characterization of older women in popular culture as helpless and in a negative fashion (e.g. Mrs Emery, Nora Batty and Mrs Richards). ${ }^{4}$ In doing so, she reaffirms the dominant position of younger women as sexually 
attractive and desirable (Bytheway 1995; Nelson 2002) and the attractiveness of women as dependent on physicality, and more importantly, the functioning of that physicality. In this routine, Rivers' definition of sexuality is based on her relationship to sexual desire, not as the desiring one, but in a more traditional understanding of a woman as the stimulus of desire. Yet there is ambivalence surrounding Rivers' experiences as an older woman. Although such material may serve to ridicule the ageing female body, Rivers speaks from an informed and knowledgeable position - she has direct personal experience of the physical changes experienced by older women - which places her in a position of authority and marks her as someone who knows the fate that awaits the younger unknowing female audience members and thus inverts the hierarchy of the dominant younger woman and the subordinate older woman. Rivers has argued that if audiences 'can be honest and laugh about some parts of their lives - the problems of getting older, becoming fat, having a child leave home, being a woman, being ordinary - then they can be honest and laugh about all parts of life' (Rivers and Meryman 1986: 308). This honesty is evident in this routine. Yet, there is a caring side to this authority in the sense that Rivers is passing on the knowledge that she would have valued being given during her younger years and would have benefitted from, as it would have made the ageing process a more pleasant experience:

Let me tell you something. And this is why I'm glad I have the chance to discuss this because our mothers don't tell us. If our mothers told us, you would feel better, do you know what I'm saying. If my mother had said to me 'Joan, when you get old, your vagina's gonna drop, but it's a good thing because you can have sex in the bedroom and still be watching TV in the living room'. Because if you don't know, it's trouble. (Part 2, 0.54-01:20)

We see and hear Rivers transgress discursive boundaries as she discusses a body part - the vagina - that we seldom hear mentioned in popular culture and rarely discussed by an older woman herself (The Vagina Monologues is an exception here). ${ }^{5}$ Through her observations and discussions of the older woman's physiology, Rivers widens the stand-up comedy agenda. The sheer delight that is evident from some members of the audience, particularly the women in the audience, suggests that women can, and do, laugh at their bodies and the bodily changes experienced across time. Such observations told in the comic mode sit in stark contrast to another dimension of the masculine discourses surrounding stand-up comedy. Hitchens (2007) maintains that 'women do not find their own physical decay and absurdity to 
be [...] riotously amusing'. Rivers' performance and the laughter from some female members of the audience challenge such masculine discourse.

In this section of her performance, Rivers continues:

Thirty-six hour erections on 90-year-old men, oh my god, and these poor women. Even if it's ten minutes a session, that's two hundred and twelve times you have to fake an orgasm. How often can you say 'you're the best, you're the best, you're the best?' A nightmare, a nightmare [...] And do you know who I feel sorry for, not the men, it's these poor wives, these poor dry old wives, and these guys on top of them, in and out, in and out, in and out, they're gonna set them on fire. (Part 2, 1:54-3:03)

This routine may be viewed as reinforcing and continuing the negative image of the older woman and her deteriorating physiology, evident earlier in her routine when discussing her 'dropping' body. Such material augments western society's male-defined understanding of femininity and subordination of women, and may reaffirm the stereotype of older women seen elsewhere in popular culture as sexually inactive when compared with older men. As Palmer observes, in the late 1960s Legman argued that, 'dirty jokes incorporate a vision of women which corresponds to masculinity' as they uphold the 'primacy of coitus, the universal availability of women, the subordination of women's discourse to male discourse and in general portray woman as an object' (1994: 73).

Although Rivers' material, as discussed above, can be viewed as objectifying women, Rivers' own appearance, to some extent, serves to neutralize this construction. Although Rivers has had cosmetic surgery, has manicured nails and professionally groomed hair, her clothes, which have been described as 'stylishly conservative' (Horowitz 1997: 93), serve to desexualize her - she reveals little flesh and conceals her body shape by wearing long loose trousers, a high polo neck and a loose cardigan. This is maybe a deliberate strategy employed by Rivers to facilitate negotiation of the male-dominated comedyscape and to prevent her from being objectified as a woman. Gray has argued that for female stand-up comedians 'to look physically threatening, to express enjoyment of sexuality, to be overtly feminist, is to become an object of laughter. To maintain her role as subject, a woman has to endorse patriarchal attitudes while distancing herself from the stereotype' (1994: 137). Rivers' material reinforces patriarchal stereotypes of women; she presents herself in a physically 
unthreatening desexualized manner and does not express enjoyment of sexual intercourse she either has not experienced such activities or can appreciate how difficult sexual relationships are for older women - thus enabling herself to be positioned as a subject rather than an object.

Such comedic contradictions are evident elsewhere in Rivers' stand-up comedy performance. Rivers simultaneously reinforces and challenges the stereotype that 'older women are invisible' (Cohen 2002: 609). The above extract about men not looking at menopausal or post-menopausal women ridicules the older woman who tries to delay the onset of fading from view, or more specifically, from masculine view, by dropping her unnecessary tampons in public. Yet, as an older female stand-up comedian, Rivers commands the stage and she stands alone - on show and easily visible - holding a central position in the performance space and refusing to fade from view. Therefore, Rivers is able to contest the masculine discourses that perpetuate the male-dominated comedyscape.

\section{Discussion}

The sociocultural analysis has revealed that Rivers' stand-up comedy performance is one that is defined by contradictions and paradoxes. From her appearance to her joke content, Rivers is an interesting synthesis of complexity, drawing on features of stand-up performance that for some critics are 'traditionally masculine' and others that have often been employed by other female stand-up comedians. Her professionally groomed and manipulated body, face, nails and hair sit in opposition to the aggressive self-deprecating narratives of having no sex appeal and few sexual encounters. Although some of the jokes told may objectify women, Rivers wears loose flowing attire that desexualizes her, which inhibits the possibility of Rivers being objectified as a woman. Yet at other moments in the stand-up comedy performance, she deliberately becomes the objectified older woman. Throughout and across the stand-up comedy performance analysed, Rivers proffers a playfulness surrounding contemporary identity constructions. Some jokes, comic observations and comic narratives challenge and resist traditional notions of femininity; others support and maintain patriarchal views of society, whereas in others, often within the same joke or observation, resisting is intertwined with sustaining dominant discourses surrounding gender and sexuality. These constructions are fluid and flexible, and ebb and flow through and across the stand-up comedy performance. Rivers moves from the subject to the object of comedy with performative ease, whilst simultaneously reinforcing and challenging stereotypes related to gender, sexuality and the ageing female body. 
Sociocultural analyses of stand-up comedy performances are important as they provide interesting insights into the ways in which the performer negotiates the comedy space in relation to her/his own identity, the identity dynamics of the audience and the wider societal beliefs, values and ideologies. Although this article has focussed on the importance of Rivers' gender and sexuality (and in a more limited manner, age) and how this is manifest in the comedic performance, it is not the intention of the analysis presented to suggest that sexuality and gender are the most important dynamics in sociocultural analysis, nor is it to suggest that Rivers' performance can only be understood in relation to its relationship to gender and sexual stereotypes and ideologies. Other spheres of identity, such as race, ethnicity, nationality, ability, disability, religion and social class, are equally as important and interesting when analysing how stand-up comedians navigate the comedyscape. For example, religion plays an interesting role in Rivers' Live at the Apollo performance - she recalls how she 'had a very bad childhood, that's because, and I'm sure none of you give a damn but, I was the only Jewish kid, this is the absolute truth, growing up in an all-Catholic neighbourhood' (Part 1, 6:43-6:53). Future sociocultural analyses could examine how religion interacts with other aspects of identity in order to extend the analysis. Finally, one of the most important contributions made by the sociocultural analysis presented in this article is to illustrate and make clear that women can be, and are, funny stand-up comedians.

\section{References}

Bakhtin, M. M. (1984), Rabelais and His World (trans. H. Iswolsky), Bloomington: Indiana University Press.

Barrick, A. L., Hutchinson, R. L. and Deckers, L. H. (1990), 'Humor, aggression and ageing', The Gerontologist, 30:5, pp. 675-678.

Bell, J. (1992), 'In search of a discourse on ageing: the elderly on television', The

Gerontologist, 32:3, pp. 305-311.

Bendelack, S., Lipsey, M., Lowney, D. and Posner, G. (2003-2006), Little Britain, BBC.

Beynon, J. (ed.) (2002), Masculinities and Culture, Buckingham and Philadelphia: Open University Press.

Bytheway, B. (1995), Ageism, Maidenhead: Open University Press.

Carr, J. and Greeves, L. (2007), The Naked Jape: Uncovering the Hidden World of Jokes, London: Penguin Books.

Cellan-Jones, J. (1993-1994), Brighton Belles, ITV. 
Channel 4 (2010), 'The 100 Greatest Stand-Ups', 11 April 2010,

http://www.channel4.com/programmes/the-100-greatest-stand-ups/articles/greateststand-ups-of-all-time. Accessed 4 April 2011.

Chortle: The UK Comedy Guide (2011), 'Comedians Currently on Tour', http://www.chortle.co.uk/shows/all/?current=3. Accessed 4 April 2011.

Cohen, H. L. (2002), 'Developing media literacy skills to challenge television's portrayal of older women', Educational Gerontology, 28:7, pp. 599-620.

Davies, J. H. and Spiers, B. (1975-1979), Fawlty Towers, BBC.

Gilbert, J., Thompson, B., Lotterby, S., Butt, R. and Bell, A. J. W. (1973-2010), Last of the Summer Wine, BBC.

Gray, F. (1994), Women and Laughter, Basingstoke: Macmillan.

Harwood, J. and Giles, H. (1992), “"Don’t Make Me Laugh”: Age representations in a humorous context', Discourse \& Society, 3:3, pp. 403-436.

Hitchens, C. (2007), 'Why women aren’t funny', Vanity Fair, January, http://www.vanityfair.com/culture/features/2007/01/hitchens200701?printable=true. Accessed 4 April 2011.

Horowitz, S. (1997), Queens of Comedy: Lucille Ball, Phyllis Diller, Carol Burnett, Joan Rivers, and the New Generation of Funny Women, London and New York: Routledge.

Hughes, T. (1985-1992), The Golden Girls, NBC.

Nelson, T. D. (ed.) (2002), Ageism, Stereotyping and Prejudice Against Older Persons, Cambridge, MA: MIT Press.

Nilsen, A. P. and Nilsen, D. L. F. (2000), Encyclopedia of $20^{\text {th }}$ Century American Humor, Arizona: Oryx Press.

Palmer, J. (1994), Taking Humour Seriously, London and New York: Routledge.

Peterson, R. T. and Ross, D. T. (1997), 'A content analysis of the portrayal of mature individuals in television', Journal of Business Ethics, 16:4, pp. 425-433.

Provine, R. (1996), 'Laughter', American Scientist, 84:January-February, pp. 38-47, http://cogweb.ucla.edu/Abstracts/Provine_96.html. Accessed 25 May 2010.

Rivers, J. (1997), Bouncing Back: I've Survived Everything... and I Mean Everything... and You Can Too!, New York: HarperCollins.

Rivers, J. and Meryman, R. (1986), Enter Talking, New York: Delacorte Press.

Ross, A. (1998), The Language of Humour, London and New York: Routledge. 
Smith, P. (ed.) (1996), Boys: Masculinities in Contemporary Culture, Boulder, CO:

Westview Press.

Sontag, S. (1972), 'The double standard of aging', Saturday Review of Society, 23:1, pp. 2938.

Wagg, S. (1998), 'Punching Your Weight: Conversations with Jo Brand', in S. Wagg (ed.), Because I Tell a Joke or Two: Comedy, Politics and Social Difference, London and New York: Routledge, pp. 111-136.

Wheeler, P. (2004-present), Live at the Apollo, BBC.

Zillman, D. and Stocking, S. H. (1976), 'Putdown humor', Journal of Communication, 26:3, pp. 154-163.

Zoglin, R. (2009), Comedy At The Edge: How Stand-up in the 1970s Changed America, New York: Bloomsbury.

\section{Acknowledgements}

Grateful thanks to Margaret Montgomerie and Liz Sutton for their useful and insightful comments on an earlier draft of the article.

\section{Contributor details}

Sharon Lockyer is a Lecturer in Sociology and Communications at Brunel University, UK. She researches in the sociology of mediated culture and critical comedy studies. She is the editor of Reading Little Britain: Comedy Matters on Contemporary Television (Tauris 2010) and a co-editor (with Michael Pickering) of Beyond a Joke: the Limits of Humour (Palgrave 2005, 2009). She has published in a range of academic journals including Social Semiotics, Popular Communication: the International Journal of Media and Culture, Journalism Studies, International Journal of Social Research Methodology: Theory \& Practice, Ethical Space: the International Journal of Communication Ethics, and Discourse \& Society.

Contact:

Sociology and Communications, School of Social Sciences, Brunel University, Uxbridge, Middlesex, UB8 3PH

E-mail: Sharon.Lockyer@brunel.ac.uk 


\section{Notes}

${ }^{1}$ Part 1 can be found at http://www.youtube.com/watch?v=YNUkLzi46OI\&feature=related. Part 2 can be found at http://www.youtube.com/watch?v=WXEt2gYcweQ\&feature=related. Accessed 28 May 2010, 1 June 2010, 4 April 2011, 16 May 2011 and 23 May 2011.

${ }^{2}$ Rivers' comedy was inspired by the outrageous and no-holds-barred comedy of Lenny Bruce (Rivers 1997).

${ }^{3}$ The British remake of The Golden Girls was called Brighton Belles (James Cellan Jones, 1993-1994) and was less successful than its US counterpart, lasting only two series.

${ }^{4}$ Mrs. Emery (played by David Walliams) in the British sketch show, Little Britain (Steve Bendelack, Matt Lipsey, Declan Lowney and Geoff Posner, 2003-2006), is an incontinent old woman who urinates uncontrollably (and unknowingly) in public places, from libraries to supermarkets, much to horror of observers and passers-by. Nora Batty (played by Kathy Staff) in Last of the Summer Wine (James Gilbert, Bernard Thompson, Sydney Lotterby, Ray Butt and Alan J. W. Bell, 1973-2010) is a Northern 'battleaxe', and Mrs. Richards (played by Joan Sanderson) in Fawlty Towers (John Howard Davies and Bon Spiers, 1975-1979) is a partially blind, deaf and bad-tempered older woman.

${ }^{5}$ The Vagina Monologues is a play written by Eve Ensler, which has been staged internationally and produced for television by HBO. 